\title{
Systematic review of the incidence of post- operative trichiasis in Africa
}

\author{
Grace Mwangi ${ }^{1 *}$ D, Paul Courtright ${ }^{2}$ and Anthony W Solomon ${ }^{3}$
}

\begin{abstract}
Background: Surgery for trichiasis is one of the pillars of the World Health Organization's strategy for global elimination of trachoma as a public health problem. A high incidence of post-operative trichiasis or other poor surgical outcomes could jeopardize these efforts. In this review, we aimed to summarize the reported incidence of post-operative trichiasis and other poor outcomes of trichiasis surgery in Africa.

Methods: We conducted a systematic literature search using PubMed, Academic Search Premier, Africa-Wide Information, CINAHL and Health Source Nursing through EBSCOhost, Web of Science, and the Cochrane Central Register of Controlled Trials. Reference lists of included studies were also reviewed to identify further potentially relevant publications. All observational and interventional studies that measured post-operative trichiasis in Africa as an outcome of trichiasis surgery were included.
\end{abstract}

Results: Thirty-five papers reporting on 22 studies (9 interventional,13 observational; total 13,737 participants) met the inclusion criteria. The reported incidence of post-operative trichiasis in the included studies ranged from $2 \%$ (at 6 weeks after bilamellar tarsal rotation) to $69 \%$ (at 3 weeks after anterior lamellar repositioning). The incidence varied by surgical procedure, study design, and length of follow-up.

Conclusion: Trichiasis surgical outcomes should be improved. National trachoma programmes could benefit from identifying and adopting strategies to improve the performance and quality of their surgical service.

Keywords: Trachoma, Trichiasis, Entropion, Post-operative trichiasis, Incidence, Eyelid diseases, Surgery

\section{Background}

Trachoma is the leading infectious cause of blindness worldwide. It is caused by particular strains of the intracellular bacterium Chlamydia trachomatis, believed to be transmitted through infected eye and nose secretions carried on fingers, fomites and eye-seeking flies [1, 2]. Repeated infection leads to scarring of the tarsal conjunctiva, which can then lead to trichiasis (eyelashes touching the eyeball) [3]. Left untreated, trachomatous trichiasis can result in the formation of corneal opacities, which irreversibly impair vision [4].

\footnotetext{
* Correspondence: grace.mwangi@alumni.uct.ac.za

'Department of Surgery, Division of Ophthalmology, University of Cape Town, Cape Town, South Africa

Full list of author information is available at the end of the article
}

Surgery is an integral part of the SAFE strategy (Surgery, Antibiotics, Facial cleanliness, Environmental improvement) advocated by World Health Organization (WHO) for elimination of trachoma as a public health problem [5]. Surgery for trichiasis aims to re-position the eyelid margin by externally rotating it so that eyelashes no longer touch the eyeball. Not all cases of trichiasis are due to trachoma and not all cases of trachomatous trichiasis involve entropion; other management approaches may be preferable when correction of entropion is not indicated. When appropriately performed, apart from preserving vision, surgery has also been shown to enhance patient comfort due to decreases in pain and photophobia, and resolution of corneal swelling [6]. Surgery substantially increases quality of life for individuals with trichiasis, even if vision itself does not improve [7]. However, for surgery to be effective in 
preventing trachoma-related blindness and to encourage other trichiasis patients to consent to an operation, there must be good long-term surgical outcomes with a low incidence of post-operative trichiasis.

WHO's third global scientific meeting on trachoma [8], convened in 2010, recommended that national trachoma programmes should report the incidence of post-operative trichiasis, and target a cumulative postoperative trichiasis incidence of $\leq 10 \%$ at one-year postsurgery. However, several studies report incidence estimates that are considerably higher than this [9]. There are only limited operational data on the incidence of post-operative trichiasis published from settings where trachoma elimination programmes are active [9].

Generating an evidence-based understanding of the magnitude and determinants of post-operative trichiasis would help inform discussions on current outcome targets and strategies to improve surgery outcomes for trichiasis. This review aims to partially fill this gap by consolidating data on incidence of post-operative trichiasis and other poor outcomes of trichiasis surgery from observational and interventional studies conducted in Africa.

\section{Methods}

\section{Ethical approval}

The protocol was approved by the University of Cape Town Faculty of Health Sciences' Human Research Ethics Committee $(076 / 2018)$ and deemed by the WHO Ethics Review Committee to not require full formal ethics review (0003034). The protocol was registered on PROSPERO: CRD42018085253.

\section{Search strategy}

We undertook a systematic search of PubMed, Academic Search Premier, Africa-Wide Information, CINA HL and Health Source Nursing through EBSCOhost, Web of Science [all databases], and the Cochrane Central Register of Controlled Trials, including material published up to and including the month of May 2018. In addition, Google Scholar and the reference lists of relevant reviews and all eligible papers were searched to cross-check for studies not already identified. Websites of organizations identified in published studies were searched for pertinent grey literature. No language limitations were applied in these searches.

The full search strategy is provided as a supplemental file.

\section{Study selection}

Two reviewers (GM, PC) independently screened the titles and abstracts of the articles found to determine their potential eligibility for inclusion. The full texts of potentially eligible studies were obtained. Selection for inclusion into the review was conducted by the two reviewers working independently. Any disagreements regarding inclusion of studies were resolved by discussion or by consulting the third reviewer (AWS).

Included studies met the following criteria: 1) conducted within Africa; 2) measured post-operative trichiasis (defined as the presence of one or more eyelashes touching the eyeball or evidence of epilation of inturned eyelashes after surgery) as an outcome; 3) included participants aged $\geq 15$ years with previously unoperated trachomatous trichiasis in at least one eye within either [a] an interventional or [b] observational study.

Editorial articles, reviews, expert opinion pieces, conference papers and meeting abstracts were excluded, as were studies conducted outside Africa, studies that did not have a surgical intervention, and those that did not measure or report post-operative trichiasis as an outcome. Any studies published before 1990 were also excluded.

We divided studies into two groups - observational and interventional studies - with the expectation that surgeons operating in the latter were more likely to be highly selected and re-trained before the study than those in the former. It should be noted however, that some interventional studies included in this review did not report criteria-based selection or re-training of surgeons before the intervention.

\section{Qualitative assessment of studies}

The methodological quality of the papers included in this review was assessed using a slight adaptation of the Joanna Briggs Institute critical appraisal checklist for prevalence studies [10]. Critical appraisal was conducted by two reviewers independently, with disagreements resolved through discussion or by consulting the third reviewer.

\section{Assessment of heterogeneity}

Studies included in this systematic review were checked for heterogeneity by examining their characteristics (study design, population, follow up period, etc.) and risk of bias. Statistical heterogeneity was assessed using $\mathrm{I}^{2}$ and Chi [2] tests. Heterogeneity was considered as significant if the $\mathrm{I}^{2}$ was above $50 \%$.

\section{Data synthesis}

The studies included in this review were varied in terms of design, interventions, follow up period and outcomes. As a result, there was high statistical heterogeneity which precluded pooling of data for the outcomes $\left(\mathrm{I}^{2}>=95 \%\right)$. RevMan 5.3 software [11] was used for all quantitative data analyses in this review.

For the intervention studies, treatment effects were measured by calculating odds ratios for the different interventions and 95\% confidence interval for these. Dichotomous data from these studies are presented in forest plots without a summary estimate, and as a narrative summary. For observational studies, data are presented as a 
percentage of those who developed the outcome of interest out of the total number of study participants.

\section{Results}

\section{Results of the search}

Initial electronic literature searches yielded 5003 articles. After removal of duplicates and a review of titles and abstracts of these and other articles identified by handsearching, 97 publications were selected for detailed review and possible inclusion. Of these, 61 articles were excluded for the following reasons: conducted outside Africa $(n=23)$; did not measure post-operative trichiasis as an outcome $(n=21)$; the condition of interest was not trichiasis due to trachoma $(n=3)$; the article type was a review, editorial or expert opinion piece $(n=14)$. One prospective study [12] was subsequently also excluded from the review, despite having met the inclusion criteria, due to internal inconsistencies in the description of study methods and findings. Ultimately, 35 articles describing 22 studies (nine interventional and 13 observational studies with a combined total of 13,737 participants) were included. Figure 1 summarizes the flow of the paper identification and selection process. A list of excluded studies is provided as a Supplementary file.

\section{Study characteristics and quality}

Table 1 summarises the characteristics and quality of the 22 studies that met the inclusion criteria. In the

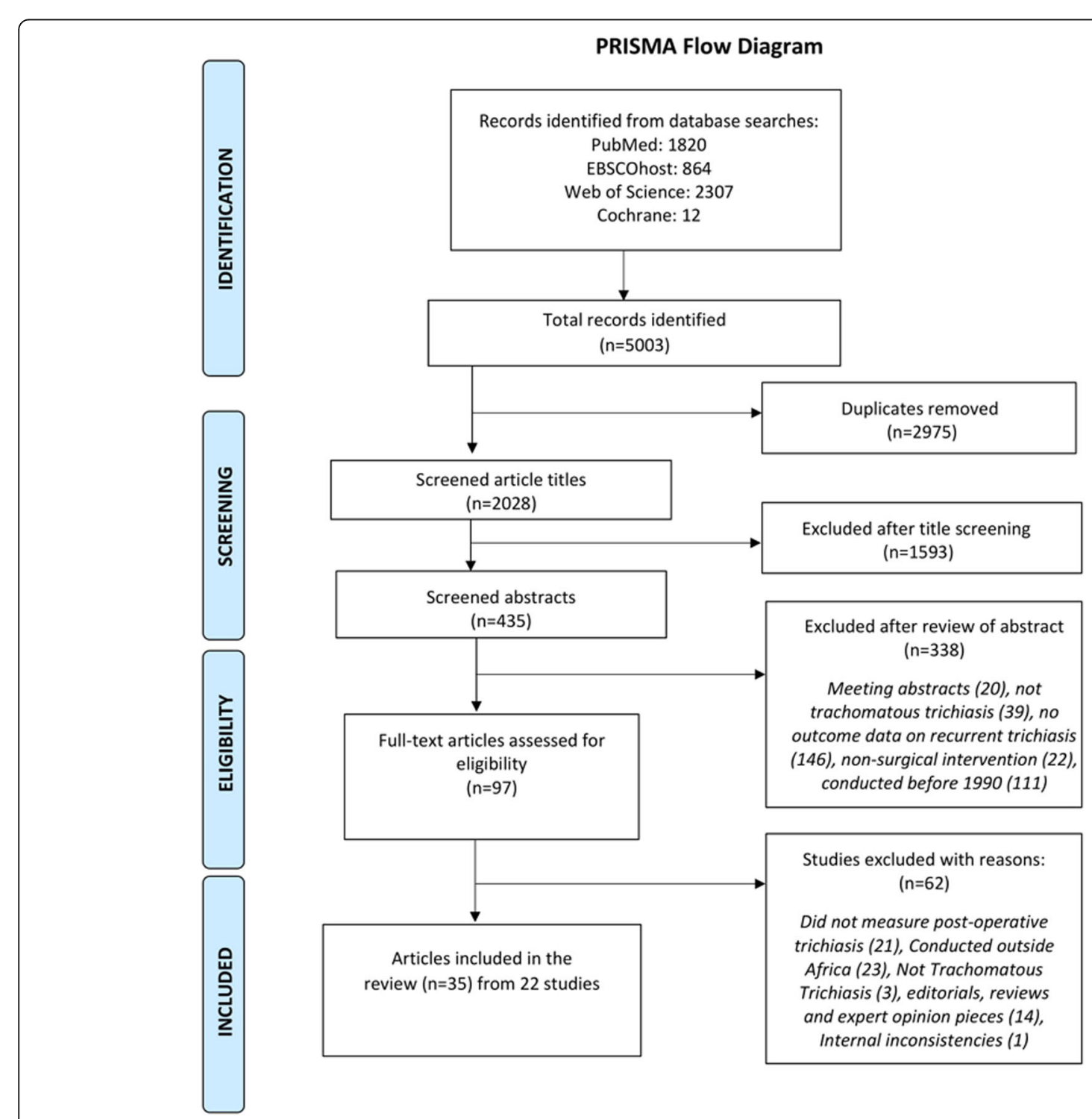

Search completed on 09 May 2018

Fig. 1 PRISMA Flow diagram 
Table 1 Characteristics of included studies

\begin{tabular}{|c|c|c|c|c|c|c|}
\hline First author, Year & Country & Study Design & $\begin{array}{l}\text { No of } \\
\text { patients }\end{array}$ & Type of surgery & Intervention $^{\mathbf{a}}$ & $\begin{array}{l}\text { Length of follow- } \\
\text { up }\end{array}$ \\
\hline \multicolumn{7}{|l|}{ a) Interventional studies } \\
\hline Adamu, 2002 [13] & Ethiopia & $\mathrm{RCT}$ & 153 & BLTR and TTR & $\begin{array}{l}\text { Surgical technique: } \\
\text { BLTR vs TTR }\end{array}$ & 3 months \\
\hline Alemayehu, 2004 [14] & Ethiopia & RCT & 982 & BLTR & $\begin{array}{l}\text { Personnel performing } \\
\text { surgery: ophthalmologist } \\
\text { vs IECWs }\end{array}$ & $\begin{array}{l}3 \text { months and } \\
6 \text { months }\end{array}$ \\
\hline Burton, 2005a [15] & The Gambia & $\mathrm{RCT}$ & 451 & PLTR & Perioperative azithromycin & $\begin{array}{l}6 \text { months and } \\
1 \text { year }\end{array}$ \\
\hline Burton, 2012 [16] & \multirow[t]{2}{*}{ Ethiopia } & \multirow[t]{2}{*}{$\mathrm{RCT}$} & \multirow[t]{2}{*}{1300} & \multirow[t]{2}{*}{ PLTR } & \multirow{2}{*}{$\begin{array}{l}\text { Absorbable sutures vs silk } \\
\text { sutures }\end{array}$} & \multirow[t]{2}{*}{1 year } \\
\hline Rajak, $2011 a$ [17] & & & & & & \\
\hline Gower, 2011 [18] & \multirow[t]{4}{*}{ Ethiopia } & \multirow[t]{4}{*}{$\mathrm{RCT}$} & \multirow[t]{4}{*}{1452} & \multirow[t]{4}{*}{ BLTR } & \multirow[t]{4}{*}{ Perioperative azithromycin } & \multirow{4}{*}{$\begin{array}{l}6 \text { weeks, } 1 \text { year } \\
\text { and } 3 \text { years }\end{array}$} \\
\hline West, 2006 [19] & & & & & & \\
\hline West, 2007 [20] & & & & & & \\
\hline Woreta, 2012 [21] & & & & & & \\
\hline Gower, 2013 [22] & Tanzania & $\mathrm{RCT}$ & 1917 & BLTR & $\begin{array}{l}\text { Tा clamp vs standard } \\
\text { procedure }\end{array}$ & 2 years \\
\hline Rajak, 2011b [23] & \multirow[t]{2}{*}{ Ethiopia } & \multirow[t]{2}{*}{$\mathrm{RCT}$} & \multirow[t]{2}{*}{1300} & \multirow[t]{2}{*}{ PLTR } & \multirow[t]{2}{*}{ PLTR vs epilation } & \multirow{2}{*}{$\begin{array}{l}2 \text { years and } 4 \\
\text { years }\end{array}$} \\
\hline Habtamu, 2015 [24] & & & & & & \\
\hline $\begin{array}{l}\text { Habtamu, } 2016[25] \\
2017 \mathrm{a}[26] \\
2017 \mathrm{~b}[27]\end{array}$ & Ethiopia & $\mathrm{RCT}$ & 1000 & PLTR and BLTR & $\begin{array}{l}\text { Surgical technique: PLTR } \\
\text { vs BLTR }\end{array}$ & 1 year \\
\hline Habtamu, 2018 [28] & Ethiopia & $\mathrm{RCT}$ & 1000 & PLTR & $\begin{array}{l}\text { Postoperative oral } \\
\text { doxycycline vs placebo }\end{array}$ & 1 year \\
\hline \multicolumn{7}{|c|}{ b) Observational studies } \\
\hline Ahmed, 2015 [29] & Egypt & $\begin{array}{l}\text { Prospective } \\
\text { non-comparative study }\end{array}$ & 445 & $\begin{array}{l}\text { Anterior lamellar } \\
\text { reposition }\end{array}$ & - & $\begin{array}{l}3 \text { weeks, } 3 \text { months } \\
\text { and } 6 \text { months }\end{array}$ \\
\hline Assefa, 2008 [30] & Ethiopia & Prospective study & 455 & TTR & - & 1 year \\
\hline Bog, 1993 [31] & Tanzania & $\begin{array}{l}\text { Prospective } \\
\text { community-based study }\end{array}$ & 94 & Tarsal plate rotation & - & 9-36 months \\
\hline Bouazza, 2017 [32] & Ethiopia & $\begin{array}{l}\text { Descriptive } \\
\text { cross-sectional study }\end{array}$ & 26 & $\begin{array}{l}\text { Anterior lamellar } \\
\text { resection with lid } \\
\text { margin splitting }\end{array}$ & - & 6 months \\
\hline Bowman, 2000 [33] & The Gambia & $\begin{array}{l}\text { Retrospective } \\
\text { Cross-sectional study }\end{array}$ & 65 & $\begin{array}{l}\text { Tarsal rotation } \\
\text { procedure }\end{array}$ & - & 7 years \\
\hline Burton, 2005b [34] & The Gambia & $\begin{array}{l}\text { Retrospective } \\
\text { cohort study }\end{array}$ & 162 & PLTR & - & 3.5 years \\
\hline Burton, 2010 [35] & The Gambia & $\begin{array}{l}\text { Prospective } \\
\text { cohort study }\end{array}$ & 240 & PLTR & - & 4 years \\
\hline el Toukhy, 2006 [36] & Egypt & Prospective study & 493 & BLTR & - & 8 to 10 weeks \\
\hline Kerie, 2010 [37] & Ethiopia & Cross-sectional survey & 780 & BLTR & - & 3 months \\
\hline Khafagy, 2012 [38] & Egypt & Prospective study & 10 & $\begin{array}{l}\text { Combined eyelid } \\
\text { splitting and selective } \\
\text { cryotherapy }\end{array}$ & - & 6 months \\
\hline $\begin{array}{l}\text { Merbs, } 2005[39] \\
\text { West, } 2005[40]\end{array}$ & Tanzania & $\begin{array}{l}\text { Retrospective } \\
\text { cohort study }\end{array}$ & 384 & BLTR & - & $>18$ months \\
\hline Merbs, 2015 [41] & Tanzania & $\begin{array}{l}\text { Preliminary data analysis } \\
\text { from the PRET trial }\end{array}$ & 145 & BLTR & - & 1 year \\
\hline Ndoye, 1997 [42] & Senegal & Retrospective study & 137 & PLTR & - & 2 years \\
\hline Négrel, 2000 [43] & Morocco & Cross-sectional survey & 740 & BLTR & - & 6 months \\
\hline Pearson, 2013 [44] & Ethiopia & Cross-sectional survey & 363 & BLTR & - & 11 months \\
\hline
\end{tabular}


Table 1 Characteristics of included studies (Continued)

\begin{tabular}{|c|c|c|c|c|c|c|}
\hline First author, Year & Country & Study Design & $\begin{array}{l}\text { No of } \\
\text { patients }\end{array}$ & Type of surgery & Intervention ${ }^{\mathbf{a}}$ & $\begin{array}{l}\text { Length of follow- } \\
\text { up }\end{array}$ \\
\hline Rajak,2010 [45] & The Gambia & Prospective study & 356 & PLTR & - & 4 years \\
\hline Rajak, 2013 [46] & Ethiopia & Prospective study & 1300 & PLTR & - & 2 years \\
\hline Woreta, 2009 [6] & Ethiopia & $\begin{array}{l}\text { Prospective study } \\
\text { within the STAR trial }\end{array}$ & 448 & BLTR & - & 6 months \\
\hline
\end{tabular}

${ }^{a}$ Only for intervention studies

22 studies, the duration of follow-up ranged from 3 weeks to more than 7 years. The incidence of postoperative trichiasis varied widely, from $2.3 \%$ [18] to 65\% [33] (Table 1). Bilamellar tarsal rotation (BLTR) and posterior lamellar tarsal rotation (PLTR; sometimes referred to as the Trabut procedure) were the most commonly reported procedures, used in 16 and 13 studies respectively. Other procedures used were anterior lamellar rotation; transverse tarsotomy and lid margin rotation; and lid margin split [13, 29, 32]. We included all eligible studies regardless of the surgical procedure used, though BLTR and PLTR are the two procedures recommended by WHO for treatment of trachomatous trichiasis [47]. Twenty of the 22 studies included in this review had relatively low risk of bias from the design, conduct and analysis standpoint. Two observational studies $[32,38]$ had relatively small sample sizes which might have affected their study power. Findings from those two studies should therefore be interpreted with caution.

\section{Primary outcomes}

\section{Follow-up period of $\leq 3$ months}

In a study conducted in Ethiopia, 2.3\% (59/2601) of operated eyelids were reported to have developed post-operative trichiasis by 6 weeks after BLTR [18].. An additional 1.3\% (35/2601 eyelids) had eye closure defects, $1.2 \%(22 / 1881)$ had eyelid contour abnormalities and $10.5 \%(198 / 1881)$ had granulomata by 6 weeks [18]. In contrast, a previous study conducted in Egypt reported an incidence of $16.4 \%$ (98/599) amongst operated eyelids at 8 weeks after BLTR [36]. In the latter study, pre-operative corneal staining, corneal opacity and the use of silk sutures were identified as risk factors for early failure of BLTR. Other risk factors associated with post-operative trichiasis and other poor outcomes include surgeon's experience and technique, short incision lengths, baseline severity of disease and epilation before surgery $[18,36]$.

Two intervention studies reported similar incidence of post-operative trichiasis; $10.4 \%$ [13] (12/115 patients) and $11.4 \%$ [14] (81/713 eyelids), while an observational study [37] conducted in Ethiopia reported a much higher incidence of post-operative trichiasis of $23.4 \%$ (308/1317 eyelids); 95\% CI: 19.0-27.8), 6 months after BLTR. In the first study [13], the incidence of post-operative trichiasis was lower in the BLTR group compared to the TTR group (OR 0.84; 95\% CI: 0.37-1.86), although this difference was not statistically significant. In the second intervention study [14], the incidence of post-operative trichiasis was higher in the intervention group (those operated on by an ophthalmologist) compared to those operated on by integrated eye care workers (OR 1.32; 95\% CI: $0.83-2.11$ ). In all 3 studies, a number of other poor outcomes were noted, including overcorrection, lid notching, pyogenic granuloma, local madarosis and conjunctival and eyelid inflammation [13, 14, 37].

\section{Follow-up period: over 3 months but less than 1 year}

A randomized controlled trial conducted in The Gambia to investigate whether perioperative single-dose oral azithromycin could improve surgical outcomes after trichiasis surgery reported a cumulative incidence of $31.5 \%$ (129/410 patients) post-operative trichiasis 6 months after PLTR [15]. In this study, the incidence of postoperative trichiasis was higher in the intervention (azithromycin) group compared to the usual care

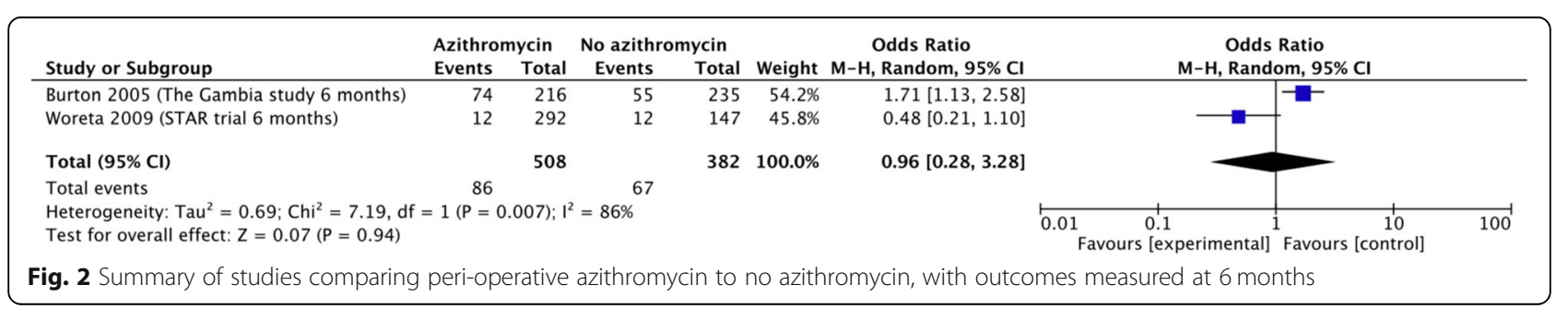




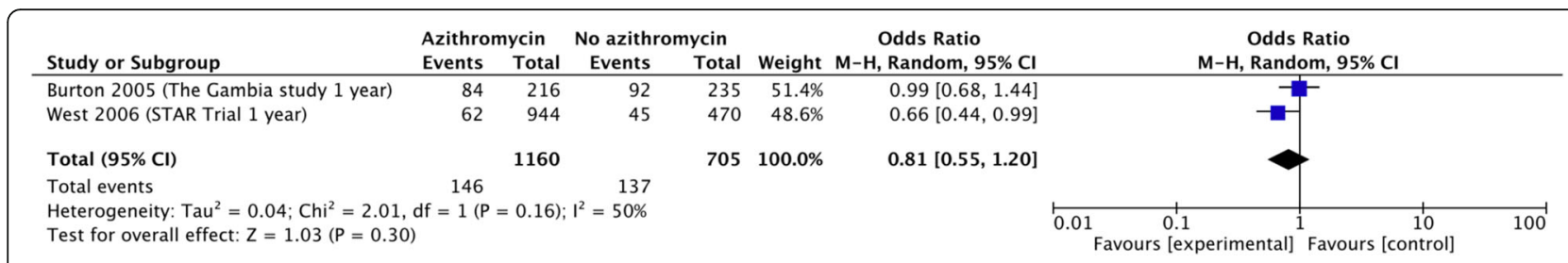

Fig. 3 Summary of studies comparing peri-operative azithromycin to no azithromycin, with outcomes measured at 1 year

(tetracycline eye ointment) group; 37.2\% (74/199) versus $26.1 \%$ (55/211 patients) [15], but in multivariable logistic regression models there was no statistically significant difference between the groups. However, post-operative trichiasis was significantly associated with severity of preoperative disease and inter-surgeon variability [15]. In contrast, the Surgery for Trichiasis, Antibiotics to Prevent Recurrence (STAR) Trial conducted in Ethiopia reported a relatively low incidence of PTT; 4.6\% (36/790 operated eyelids); $4.2 \%$ in the azithromycin group, $7.9 \%$ in the control group; OR 0.48; 95\% CI: 0.21-1.10) 6 months after BLTR [6] (Fig. 2). In the latter study, surgeons had been highly selected and retrained before the intervention; while the Gambian study employed the available community ophthalmic nurses.

Other studies with 6 months follow-up produced estimates of the incidence of post-operative trichiasis of 6.2\% (43/694 patients; 95\% CI: 4.4-8) [14] and 15.8\% (117/740 patients; CI not reported) [43] after BLTR. In a cross-sectional study conducted in Amhara Regional State of Ethiopia, 34 of the 363 patients (9.4\%; 95\% CI: 6.6-12.8) had post-operative trichiasis at 11 months after community-based trichiasis surgery with absorbable sutures. The prevalence of post-operative trichiasis reported in this study was lower than estimates reported in other observational studies although lid closure defects and lid notching were seen in 5.5\% (20/363 patients) [95\% CI: 3.4-8.4] and 16.8\% (61/362 patients) [95\% CI: 13.1-21.1] of cases respectively [44].

\section{Follow-up period of 1 year}

Among studies with a one-year follow-up period, the highest incidence of post-operative trichiasis at 41.3\% (176/426 patients) was reported in the aforementioned Gambian study after PLTR surgery [15]. Unlike at 6 months followup, when the incidence of post-operative trichiasis was higher in the intervention (azithromycin) group than in the control group, at 1 year there were fewer cases of postoperative trichiasis in the intervention than in the control group; this difference was not statistically significant. In contrast, the STAR trial $[19,20]$ reported a relatively low incidence of post-operative trichiasis $(7.6 \%$; 107/1414 patients) 1 year after BLTR with significant difference seen between those who received peri-operative azithromycin and those in the control group (OR 0.66; 95\% CI: 0.44-0.99). In combining the data from these two trials, those in the intervention (azithromycin) group were less likely to develop post-operative trichiasis (OR 0.81; 95\% CI: 0.55-1.20) but the effect was not statistically significant (Fig. 3).

A number of other intervention studies reported estimates of $>10 \%$ for the incidence of post-operative trichiasis at 1 year after surgery: $17.4 \%$ (173/992 patients) [25-27], 19\% (234/1236) [16, 17] and 12\% (120/999) [28], as summarised in Table 2.

\section{Follow-up of more than one year}

A retrospective cohort study conducted in Tanzania reported that $28 \%$ (176/630 eyes; CI not reported) of operated eyelids had developed post-operative trichiasis at 18 months after BLTR $[39,40]$. At 2 years, several intervention studies reported relatively high incidence estimates of post-operative trichiasis following either BLTR or PLTR: 39.9\% (1333/3343 eyelids) [22], 33.9\% (412/ 1216 patients) [23] and $19 \%(235 / 1218$ patients) $[16,17]$ as summarised in Table 3. One prospective cohort study [46] reported an incidence of $24.7 \%$ (315/1276 patients) 2 years after PLTR.

Similarly, at three and 4 years, high incidences of postoperative trichiasis (>20\%) were reported regardless of the surgical procedure used $[24,34,35,45]$. In the Gambia study [15], the incidence of PTT was high (41\%; 110/266 eyelids), 4 years after surgery. This was associated with increasing conjunctival inflammation at 4 years [23]. The STAR trial, however, was exceptional,

Table 2 Summary of intervention studies with outcomes measured at 1 year

\begin{tabular}{llll}
\hline Study & Intervention & Participants & OR; 95\% Cl \\
\hline Habtamu 2016 [25] & PLTR vs BLTR & 992 & $0.51[0.36-0.72]$ \\
Rajak 2011 [16, 17] & PLTR with absorbable sutures vs silk sutures & 1236 & $0.98[0.73-1.30]$ \\
Habtamu 2018 [28] & PLTR with doxycycline vs placebo & 999 & $0.93[0.64-1.37]$ \\
\hline
\end{tabular}


Table 3 Summary of intervention studies with outcomes measures at $>1$ year

\begin{tabular}{llll}
\hline Study & Intervention & Participants & OR; 95\% Cl \\
\hline Gower 2013 [22] & BLTR with TT clamp vs standard procedure & 3343 & $1.32[1.15-1.52]$ \\
Rajak 2011 [16, 17] & PLTR with absorbable sutures vs silk sutures & 1218 & $0.99[0.74-1.32]$ \\
Rajak 2011b [23] & PLTR versus epilation & 1216 & $0.31[0.24-0.42]$ \\
\hline
\end{tabular}

reporting a cumulative incidence of post-operative trichiasis of only $12 \%$ (161/1322 patients) [19-21] in the 3 years after BLTR, with less post-operative trichiasis in the intervention group (OR 0.76; 95\% CI: 0.54-1.07] Fig. 4

\section{Comparison between surgical procedures and study types}

The incidence of post-operative trichiasis was high (> $20 \%$ ) across different follow-up periods regardless of the surgical procedure used (Figs. 5 and 6). Only one study provided a direct comparison between the two most common procedures for trichiasis surgery - PLTR and BLTR [25]. In this study conducted in Ethiopia, PLTR was found to yield a lower incidence of post-operative trichiasis compared to BLTR (OR 0.51; 95\% CI: 0.36-0.72).

In terms of type of study, the incidence of postoperative trichiasis varied in both interventional and observational studies. Generally, however, the cumulative incidence of PTT was lower in interventional studies [7, $17,22,24,25,27]$ than in observational studies $[29,30$, 33-35, 37, 39-41, 45, 46] (Figs. 5 and 6). Amongst ten interventional studies reporting outcomes $\leq 6$ months after surgery, the four that either re-trained or specifically selected surgeons had the lowest post-operative trichiasis incidence estimates.

At 3-6 months follow-up, two interventional studies $[13,48]$ reported comparable incidences of postoperative trichiasis: $11.4 \%$ (81/713 patients) and $14.3 \%$ (124/901 patients) at 3 and 6 months respectively following BLTR; 10.4\% (12/115 eyelids) 3 months after BLTR and $12.3 \%$ (15/122 eyelids) 3 months after transverse tarsotomy and lid margin rotation group [13]). This was significantly lower than the incidence reported in two observational studies over the same length of time: $44.7 \%$ (336/752 eyelids) [29] and 30.5\% (238/780 patients) [37].

\section{Discussion}

Our systematic review suggests that there is a huge disparity between policy and practice with respect to the incidence of post-operative trichiasis in Africa. WHO recommends that national trachoma programmes strive to achieve $\leq 10 \%$ post-operative trichiasis by 1 year after surgery [8], but in the eight studies we identified that had one-year data, only one had an incidence of postoperative trichiasis $\leq 10 \%$ [19]. This suggests that there is a need to put in place or strengthen existing measures to improve the proportion of patients achieving satisfactory outcomes. A logical approach would be for national trachoma programmes to establish and implement policies and systems to follow up patients, assess surgical outcomes and maximize the performance of individual surgeons through post-surgical audits with provision of additional support, where needed.

BLTR and PLTR are currently the most commonly used procedures, with evidence presented elsewhere suggesting that they produce better outcomes than other techniques [13, 23, 24]. Only one recent study [25] has directly compared the two. Additional research is warranted to confirm the apparent superiority of PLTR [49].

Our study has clear weaknesses for estimating the rate and determinants of success in trichiasis surgery programs; these should be acknowledged before further conclusions are drawn. We did not collect program-level data, but rather collated reported post-operative trichiasis incidence estimates from the literature, with referenced papers derived from the experience of academically supported settings over three decades. The contemporary incidence of bad outcomes when surgery was being routinely performed in unselected program delivery environments could easily have been higher (or lower) than noted, and there are too few data points and too many potential explanatory variables to try to infer possible changes in incidence over time.

\begin{tabular}{|c|c|c|c|c|c|c|c|c|}
\hline Study or Subgroup & \multicolumn{2}{|c|}{ Azithromycin } & \multicolumn{2}{|c|}{ No azithromycin } & Weight & $\begin{array}{c}\text { Odds Ratio } \\
\mathrm{M}-\mathrm{H}, \text { Random, } 95 \% \mathrm{Cl}\end{array}$ & $\begin{array}{c}\text { Odds Ratio } \\
\mathrm{M}-\mathrm{H}, \text { Random, } 95 \% \mathrm{Cl}\end{array}$ & \\
\hline Woreta 2012 (STAR trial 3 years) & 99 & 884 & 62 & 438 & $67.3 \%$ & $0.76[0.54,1.07]$ & $\rightarrow+$ & \\
\hline Burton et al 2005 (4 years) & 50 & 127 & 60 & 140 & $32.7 \%$ & $0.87[0.53,1.41]$ & & \\
\hline Total $(95 \% \mathrm{Cl})$ & & 1011 & & 578 & $100.0 \%$ & $0.80[0.60,1.05]$ & & \\
\hline Total events & 149 & & 122 & & & & & \\
\hline $\begin{array}{l}\text { Heterogeneity: } \mathrm{Tau}^{2}=0.00 ; \mathrm{Chi}^{2} \\
\text { Test for overall effect: } \mathrm{Z}=1.60(\mathrm{P}\end{array}$ & $\begin{array}{l}=0.17, \mathrm{df} \\
=0.11)\end{array}$ & $=1(P=$ & $=0.68) ; 1^{2}=$ & & & & $\begin{array}{llll}0.01 & 0.1 & 1 & 10 \\
& \text { Favours [experimental] } & \text { Favours [control] }\end{array}$ & $\overrightarrow{100}$ \\
\hline
\end{tabular}




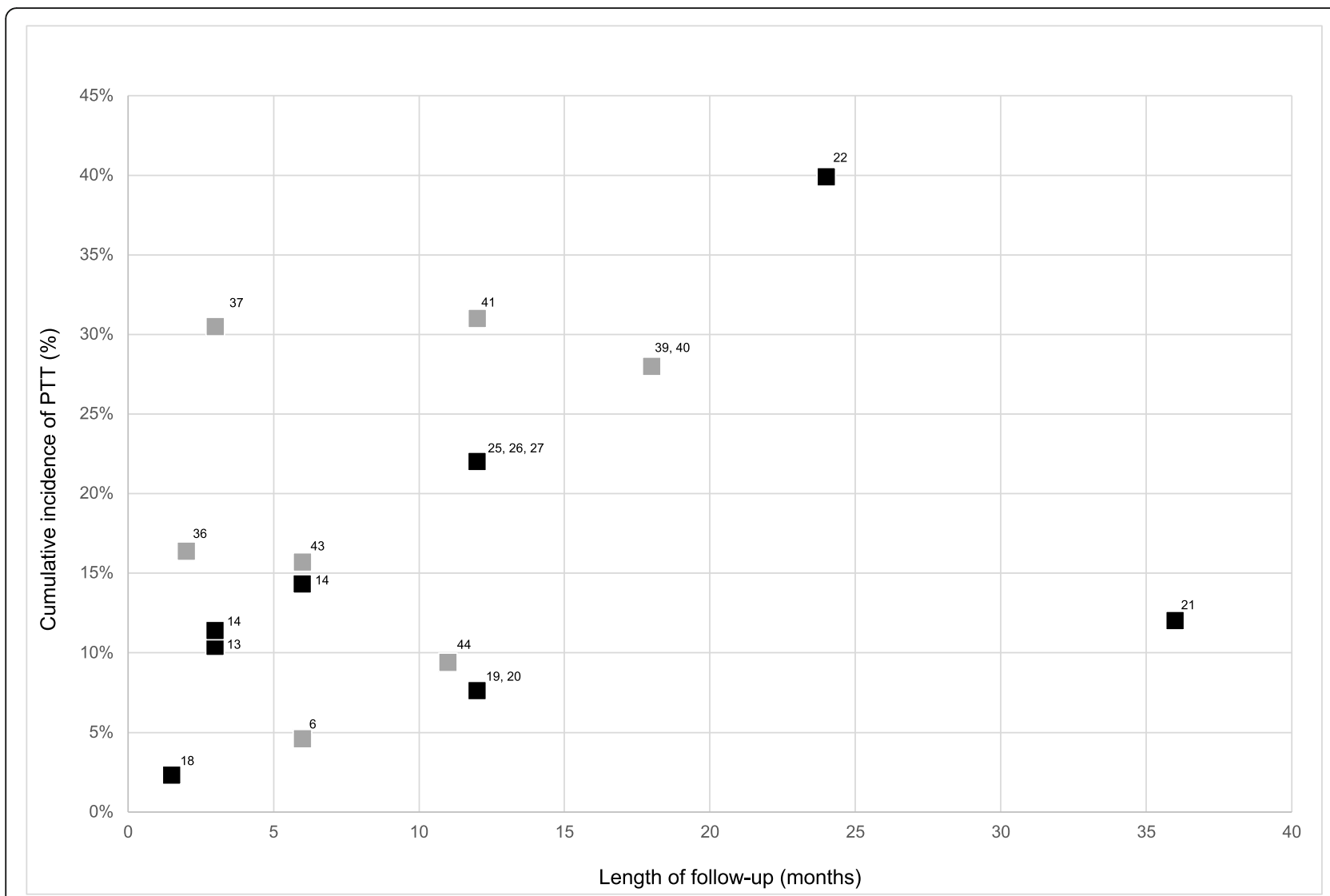

Note: Numbers next to squares indicate study reference number [Dark squares $=$ interventional; grey squares $=$ observational study]

Fig. 5 Incidence of PTT among patients who had BLTR, by type of study and duration of follow-up

Data on the phenotype of post-operative trichiasis were generally not published; the potential implications for vision of having one or two peripheral trichiatic eyelashes are likely to be considerably less than those of large numbers of central trichiatic eyelashes. It is also important to note that most studies included in this review were conducted before publication of the International Coalition for Trachoma Control's training and supervision guidelines [50,51], and before mannequinbased surgical simulation training [52] became available. These measures are likely (though formally unproven) to improve the outcomes of trichiasis surgery.

How else could success rates be optimized? A large randomized controlled trial in Ethiopia suggested that a single dose of peri-operative azithromycin was associated with a $33 \%$ reduction in post-operative trichiasis by 3 years after surgery, compared with topical tetracycline prescribed for 6 weeks [19-21]. These data differ from a smaller clinical trial comparing peri-operative oral azithromycin with two post-surgical weeks of topical tetracycline conducted in The Gambia [15], where no significant difference in outcomes was observed. One important difference between those two trials was the absence of trial-specific training and standardization of surgeons in the Gambian study, which might have resulted in a higher incidence of post-operative trichiasis; significant variability between surgeons was noted, with incidence of post-operative trichiasis ranging by surgeon from 0 to $83 \%$. The Ethiopian study [19] used surgeons who had been trained and certified by the study team prior to the start of the trial. One interpretation of this combination of findings would be that, though azithromycin might have a protective effect against postoperative trichiasis, it cannot overcome shortfalls in training, standardization and supervision of surgeons. Other differences between the two environments might also, or alternatively, be responsible. The mechanism for azithromycin having an impact, if it does, is not necessarily clear: it could potentially relate to either the antiinflammatory or anti-infective action of the macrolide.

In another randomized controlled trial conducted in Ethiopia [17], there was no evidence that use of absorbable sutures was associated with a lower incidence of post-operative trichiasis at 1 year after surgery compared to the use of silk (although absorbable sutures were found to reduce the incidence of granulomata) [16, 


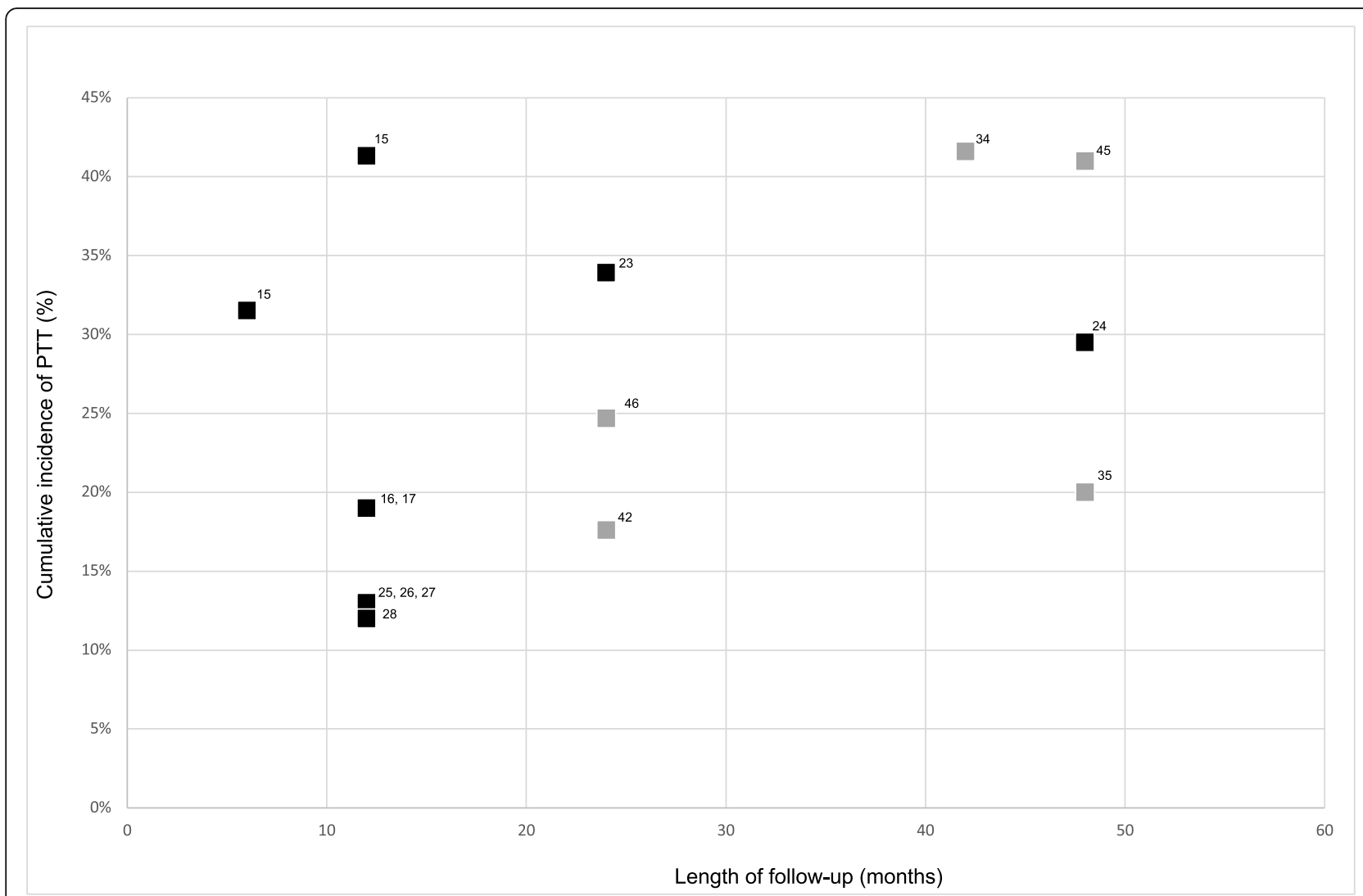

Note: Numbers next to squares indicate study reference number [Dark squares = interventional; grey squares $=$ observational study]

Fig. 6 Incidence of PTT among patients who had PLTR, by type of study and duration of follow-up

17]. Despite careful standardisation, there was significant variability in outcomes between different surgeons in this trial. To protect patients, operator-dependent factors, including dexterity, handedness, visual acuity, rigor of training and certification, supervision and motivation, must always be considered possible contributors to the occurrence of post-operative trichiasis. The tendency noted in the current review for post-operative trichiasis incidence to be lower in interventional than in observational studies was most marked for interventional studies where surgeons were re-trained prior to initiation of the study, reinforcing the (perhaps expected) point that greater skill levels drive better results.

\section{Conclusion}

Since 1990, published estimates suggest that anatomical outcomes of the surgical management of trachomatous trichiasis are worse than expected by WHO. More effort needs to be made to better understand the routine incidence, phenotype and determinants of post-operative trichiasis. This knowledge is critical to help design strategies to minimize its occurrence. In the meantime, stringent adherence to recommended follow-up schedules
[53] is recommended to ensure that patients experiencing sub-optimal outcomes are detected early and offered appropriate care.

\section{Supplementary information}

Supplementary information accompanies this paper at https://doi.org/10. 1186/s12886-020-01564-0.

\section{Additional file 1.}

Additional file 2 .

\section{Abbreviations}

BLTR : Bilamellar tarsal rotation; Cl: Confidence interval; CINAHL: Cumulative Index to Nursing and Allied Health Literature; IECWs: Integrated eye care workers; OR: Odds ratio; PLTR: Posterior lamellar tarsal rotation; PTT: Postoperative trichiasis; SAFE: Surgery, Antibiotics, Facial cleanliness,

Environmental improvement; STAR: Surgery for Trichiasis, Antibiotics to Prevent Recurrence; TTR: Transverse tarsotomy with lid margin rotation WHO: World Health Organization

\section{Acknowledgements}

We thank the Queen Elizabeth Diamond Jubilee Trust for funding GM to complete the Master of Public Health at University of Cape Town. The authors alone are responsible for the views expressed in this article and they do not necessarily represent the views, decisions or policies of the institutions with which they are affiliated. 


\section{Authors' contributions}

GM, PC and AWS contributed to the design and conduct of the study, the analysis of the results and the writing of the manuscript. All authors have read and approved the manuscript.

\section{Funding}

This study was completed as part of a Master of Public Health course funded by the Queen Elizabeth Diamond Jubilee Trust. No specific funding was obtained for the design of the study; collection, analysis, or interpretation of data; or the writing of this manuscript.

\section{Availability of data and materials}

The datasets used and/or analysed during the current study available from the corresponding author on reasonable request.

\section{Ethics approval and consent to participate}

Ethical approval was obtained from the University of Cape Town Health Sciences Research Committee and the World Health Organization Ethics Review Committee (0003034). This was a systematic review; there were no primary study subjects from whom consent needed to be obtained.

\section{Consent for publication}

Not applicable

\section{Competing interests}

The authors declare that there are no financial or non-financial competing interests.

\section{Author details}

${ }^{1}$ Department of Surgery, Division of Ophthalmology, University of Cape Town, Cape Town, South Africa. ${ }^{2}$ Kilimanjaro Centre for Community Ophthalmology, Division of Ophthalmology, University of Cape Town, Cape Town, South Africa. ${ }^{3}$ Department of Control of Neglected Tropical Diseases, World Health Organization, Geneva, Switzerland.

Received: 22 July 2019 Accepted: 10 July 2020

Published online: 17 November 2020

\section{References}

1. Gower E, Solomon AW, Burton MJ, et al. Chlamydial positivity of nasal discharge at baseline is associated with ocular chlamydial positivity 2 months following azithromycin treatment. Invest Ophthalmol Vis Sci. 2006; 47(11):4767. https://doi.org/10.1167/iovs.05-1599.

2. Miller K, Pakpour N, Yi E, et al. Pesky trachoma suspect finally caught. Br J Ophthalmol. 2004;88(6):750-1. https://doi.org/10.1136/bjo.2003.038661.

3. Gambhir M, Basáñez M-G, Burton MJ, et al. The development of an agestructured model for trachoma transmission dynamics, pathogenesis and control. PLoS Negl Trop Dis. 2009:3(6):e462. https://doi.org/10.1371/journal. pntd.0000462.

4. Taylor HR, Burton MJ, Haddad D, West S, Wright H. Trachoma. Lancet. 2014; 384(9960):2142-52. https://doi.org/10.1016/S0140-6736(13)62182-0.

5. Francis V, Turner V. Achieving community support for trachoma control (WHO/PBL/93.36). Geneva: World Health Organization; 1993.

6. Woreta TA, Munoz BE, Gower EW, Alemayehu W, West SK. Effect of trichiasis surgery on visual acuity outcomes in Ethiopia. Arch Ophthalmol (Chicago, III 1960). 2009;127(11):1505-10. https://doi.org/10.1001/archophthalmol.2009. 278.

7. Habtamu E, Wondie T, Aweke S, et al. Impact of Trichiasis Surgery on Quality of Life: A Longitudinal Study in Ethiopia. Vinetz JM, ed. PLoS Negl Trop Dis. 2016;10(4):e0004627. doi:https://doi.org/10.1371/journal.pntd. 0004627.

8. World Health Organization. Report of the Third Global Scientific Meeting on Trachoma (WHO/PBD/2.10). Geneva: World Health Organization; 2010.

9. Burton $\mathrm{M}$, Habtamu E, Ho D, Gower EW. Interventions for trachoma trichiasis. In: Burton M, ed. Cochrane Database Syst Rev. Chichester: John Wiley \& Sons, Ltd; 2015. doi:https://doi.org/10.1002/14651858.CD004008.pub3.

10. Joanna Briggs Institute. ebp - Critical Appraisal Tools. https://joannabriggs. org/ebp/critical_appraisal_tools. Accessed February 19, 2020.

11. The Nordic Cochrane Centre. Rev Manag (RevMan). Version 5.1. 2011.

12. Zbiba H, Farah H, Brahim R. New tarsotomy technique in the treatment of post trachomatous trichiasis: 3000 case reports. Tunis Med. 1993;71(5):245-8.
13. Adamu Y, Alemayehu W. A randomized clinical trial of the success rates of bilamellar tarsal rotation and tarsotomy for upper eyelid trachomatous trichiasis. Ethiop Med J. 2002;40(2):107-14.

14. Alemayehu W, Melese M, Bejiga A, Worku A, Kebede W, Fantaye D. Surgery for trichiasis by ophthalmologists versus integrated eye care workers: a randomized trial. Ophthalmology. 2004;111(3):578-84. https://doi.org/10. 1016/j.ophtha.2003.06.030

15. Burton MJ, Kinteh $\mathrm{F}$, Jallow $\mathrm{O}$, et al. A randomised controlled trial of azithromycin following surgery for trachomatous trichiasis in the Gambia. Br J Ophthalmol. 2005;89(10):1282-8. https://doi.org/10.1136/ bjo.2004.062489.

16. Burton MJ, Rajak SN, Ramadhani A, et al. Post-Operative Recurrent Trachomatous Trichiasis Is Associated with Increased Conjunctival Expression of S100A7 (Psoriasin). PLoS Negl Trop Dis. 2012;6(12). https://doi. org/10.1371/journal.pntd.0001985.

17. Rajak SN, Habtamu E, Weiss HA, et al. Absorbable versus silk sutures for surgical treatment of trachomatous trichiasis in Ethiopia: A randomised controlled trial. PLoS Med. 2011;8(12). https://doi.org/10.1371/journal.pmed. 1001137.

18. Gower EW, Merbs SL, Munoz BE, et al. Rates and risk factors for unfavorable outcomes 6 weeks after trichiasis surgery. Invest Ophthalmol Vis Sci. 2011; 52(5):2704-11. https://doi.org/10.1167/iovs.10-5161.

19. West SK, West ES, Alemayehu W, et al. Single-dose azithromycin prevents Trichiasis recurrence following surgery. Arch Ophthalmol. 2006;124(3):309. https://doi.org/10.1001/archopht.124.3.309.

20. West S, Alemayehu W, Munoz B, Gower EW. Azithromycin prevents recurrence of severe Trichiasis following Trichiasis surgery: STAR trial. Ophthalmic Epidemiol. 2007;14(5):273-7. https://doi.org/10.1080/ 09286580701410323.

21. Woreta F, Munoz B, Gower E, Alemayehu W, West SK. Three-year outcomes of the surgery for Trichiasis, antibiotics to prevent recurrence trial. Arch Ophthalmol. 2012;130(4):427. https://doi.org/10.1001/archophthalmol.2011.374.

22. Gower EW, West SK, Harding JC, et al. Trachomatous Trichiasis clamp vs standard Bilamellar tarsal rotation instrumentation for Trichiasis surgery. JAMA Ophthalmol. 2013;131(3):294. https://doi.org/10.1001/jamaophthalmol. 2013.910

23. Rajak SN, Habtamu E, Weiss HA, et al. Surgery Versus Epilation for the Treatment of Minor Trichiasis in Ethiopia: A Randomised Controlled Noninferiority Trial. Lewallen S, ed. PLoS Med. 2011;8(12):e1001136. doi: https://doi.org/10.1371/journal.pmed.1001136.

24. Habtamu E, Rajak SN, Tadesse Z, et al. Epilation for minor Trachomatous Trichiasis: four-year results of a randomised controlled trial. PLoS Negl Trop Dis. 2015;9(3):1-15. https://doi.org/10.1371/journal.pntd.0003558.

25. Habtamu E, Wondie T, Aweke S, et al. Posterior lamellar versus bilamellar tarsal rotation surgery for trachomatous trichiasis in Ethiopia: a randomised controlled trial. Lancet Glob Health. 2016;4(3):e175-84. https://doi.org/10. 1016/S2214-109X(15)00299-5.

26. Habtamu E, Wondie T, Aweke S, et al. Predictors of Trachomatous Trichiasis surgery outcome. Ophthalmology. 2017;124(8):1143-55. https://doi.org/10. 1016/j.ophtha.2017.03.016.

27. Habtamu E, Wondie T, Aweke S, et al. Impact of trichiasis surgery on daily living: A longitudinal study in Ethiopia. Wellcome Open Res. 2017;2:69. https://doi.org/10.12688/wellcomeopenres.11891.2.

28. Habtamu E, Wondie T, Aweke S, et al. Oral doxycycline for the prevention of postoperative trachomatous trichiasis in Ethiopia: a randomised, doubleblind, placebo-controlled trial. Lancet Glob Health. 2018;6(5):e579-92. https://doi.org/10.1016/S2214-109X(18)30111-6.

29. Ahmed RA, Abdelbaky SH. Short term outcome of anterior lamellar reposition in treating trachomatous trichiasis. J Ophthalmol. 2015;2015. https://doi.org/10.1155/2015/568363.

30. Assefa Y, Habte D, Yigzaw T, Mekonnen A, Gebrie T, Dubale T. Trichiasis recurrence in North Ethiopia : A one year prospective study of Trachomatous Trichiasis surgery done by integrated eye care workers. Ethiop J Health Dev. 2008;22(1).

31. Bog H, Yorston D, Foster A. Results of community-based eyelid surgery for trichiasis due to trachoma. Br J Ophthalmol. 1993;77(2):81-3. https://doi.org/ 10.1136/bjo.77.2.81.

32. Bouazza M, Elbelhadji M, Cherkaoui S, et al. Marginoplastie par recul de la lamelle antérieure dans le traitement de l'entropion trichiasis trachomateux de la paupière supérieure. J Fr Ophtalmol. 2017:40(6):453-9. https://doi.org/ 10.1016/j.jfo.2016.12.020. 
33. Bowman RJC, Jatta B, Faal H, Bailey R, Foster A, Johnson GJ. Long-term followup of lid surgery for trichiasis in the Gambia: surgical success and patient perceptions. Eye. 2000;14(6):864-8. https://doi.org/10.1038/eye.2000.238.

34. Burton MJ, Bowman RJC, Faal H, et al. Long term outcome of trichiasis surgery in the Gambia. Br J Ophthalmol. 2005;89(5):575-9. https://doi.org/10. 1136/bjo.2004.055996.

35. Burton MJ, Bailey RL, Jeffries D, et al. Conjunctival expression of matrix metalloproteinase and proinflammatory cytokine genes after trichiasis surgery. Invest Ophthalmol Vis Sci. 2010;51(7):3583-90. https://doi.org/10 1167/iovs.09-4550

36. el Toukhy E, Lewallen S, Courtright P. Routine Bilamellar tarsal rotation surgery for Trachomatous Trichiasis: short-term outcome and factors associated with surgical failure. Ophthalmic Plast Reconstr Surg. 2006;22(2): 109-12. https://doi.org/10.1097/01.iop.0000203494.49446.60.

37. Kerie A, Bejiga A. Pattern of recurrence of trachomatous trichiasis after surgery in Enemor and Ener district, Central Ethiopia. Ethiop Med J. 2010;48(4):301-8.

38. Khafagy A, Mostafa MM, Fooshan F. Management of trichiasis with lid margin split and cryotherapy. Clin Ophthalmol. 2012;6(1):1815-7. https://doi. org/10.2147/OPTH.S35678.

39. Merbs SL, West SK, West ES. Pattern of recurrence of trachomatous trichiasis after surgery: surgical technique as an explanation. Ophthalmology. 2005; 112(4):705-9. https://doi.org/10.1016/j.ophtha.2004.10.037.

40. West ES, Mkocha H, Munoz B, et al. Risk factors for postsurgical trichiasis recurrence in a trachoma-endemic area. Invest Ophthalmol Vis Sci. 2005; 46(2):447-53. https://doi.org/10.1167/iovs.04-0600.

41. Merbs SL, Oktavec KC, Munoz BE, et al. Lower postoperative scar height is associated with increased postoperative Trichiasis 1 year after Bilamellar tarsal rotation surgery. Ophthalmic Epidemiol. 2015;22(3):200-7. https://doi. org/10.3109/09286586.2015.1036299.

42. Ndoye PA, Ngom A, Ndiaye CS, et al. Trachomatous entropion trichiasis at the ophthalmologic clinic of Dantec CHU (apropos of 199 cases). Rev Int Trach Pathol Ocul Trop Subtrop Sante Publique. 1997;74:97-106.

43. Négrel AD, Chami-Khazraji Y, Arrache ML, Ottmani S, Mahjour J. The quality of trichiasis surgery in the Kingdom of Morocco. Sante. 2000;10(2):81-92.

44. Pearson K, Habte D, Zerihun $\mathrm{M}$, et al. Evaluation of community-based trichiasis surgery in Northwest Ethiopia. Ethiop J Health Sci. 2013;23(2):131-40.

45. Rajak SN, Makalo P, Sillah A, et al. Trichiasis surgery in the Gambia: a 4-year prospective study. Invest Ophthalmol Vis Sci. 2010;51(10):4996-5001. https:// doi.org/10.1167/iovs.10-5169.

46. Rajak SN, Habtamu E, Weiss HA, et al. The outcome of Trachomatous Trichiasis surgery in Ethiopia: risk factors for recurrence. PLoS Negl Trop Dis. 2013;7(8):1-11. https://doi.org/10.1371/journal.pntd.0002392.

47. Merbs S, Resnikoff S, Kello AB, Mariotti S. Trichiasis surgery for trachoma (2nd ed). Geneva: World Health Organization; 2015.

48. Alemayehu W. Surgery for trichiasis by ophthalmologists versus integrated eye care workers a randomized trial. Ophthalmology. 2004;111(3):578-84. https://doi.org/10.1016/j.ophtha.2003.06.030.

49. Solomon AW. Optimising the management of trachomatous trichiasis. Lancet Glob Health. 2016;4(3):e140-1. https://doi.org/10.1016/S2214109X(16)00004-8.

50. International Coalition for Trachoma Control. Organizing Trichiasis surgical outreach; a preferred practice for program managers in Ethiopia. London: ICTC; 2015.

51. International Coalition for Trachoma Control. Supportive supervision for Trachomatous Trichiasis Programmes. London: ICTC; 2016.

52. Gower EW, Kello AB, Kollmann KM. Training trichiasis surgeons: ensuring quality. Commun Eye Health. 2014;27(87):58,

53. World Health Organization. Informal Consultation on a Tracking System for Patients with Trachomatous Trichiasis (WHO/HTM/NTD/2016.1). Geneva: World Health Organization; 2016.

\section{Publisher's Note}

Springer Nature remains neutral with regard to jurisdictional claims in published maps and institutional affiliations.

Ready to submit your research? Choose BMC and benefit from:

- fast, convenient online submission

- thorough peer review by experienced researchers in your field

- rapid publication on acceptance

- support for research data, including large and complex data types

- gold Open Access which fosters wider collaboration and increased citations

- maximum visibility for your research: over $100 \mathrm{M}$ website views per year

At BMC, research is always in progress.

Learn more biomedcentral.com/submissions 